\title{
Dramatic HER Suppression on Ag Electrodes via Molecular Films for Highly Selective $\mathrm{CO}_{2}$ to $\mathrm{CO}$ Reduction
}

\author{
Arnaud Thevenon, ${ }^{\dagger}$ Alonso Rosas-Hernández, ${ }^{\dagger}$ Alex M. Fontani Herreros, Theodor Agapie, ${ }^{*}$ and Jonas \\ C. Peters*
}

Joint Center for Artificial Photosynthesis (JCAP) and Division of Chemistry and Chemical Engineering, California Institute of Technology (Caltech), Pasadena, California 91125, USA.

KEYWORDS: electrocatalysis, $\mathrm{CO}_{2} \mathrm{RR}$, HER, solar fuels, modified electrodes, silver electrodes.

\begin{abstract}
The carbon dioxide reduction reaction $\left(\mathrm{CO}_{2} \mathrm{RR}\right)$ in aqueous electrolytes suffers from efficiency loss due to the competitive hydrogen evolution reaction (HER). Developing efficient methods to suppress HER is a crucial step toward $\mathrm{CO}_{2}$ utilization. Herein, we report the selective conversion of $\mathrm{CO}_{2}$ to $\mathrm{CO}$ on planar silver electrodes with Faradaic efficiencies $>99 \%$ using simple pyridinium-based additives. Similar to our previous studies on copper electrodes, the additives form an organic film which alters $\mathrm{CO}_{2} \mathrm{RR}$ selectivity. We report electrochemical kinetic and other mechanistic data to shed light on the role of these organic layers in suppressing HER. These data suggest that hydrogen production is selectively inhibited by the growth of a hydrophobic organic layer on the silver surface that limits proton but not $\mathrm{CO}_{2}$ mass transport at certain applied potentials. The data also point to the involvement of a proton-transfer within the rate determining step of the catalysis, instead of the commonly observed electron-transfer step for the case of planar Ag electrodes.
\end{abstract}

\section{INTRODUCTION}

While anthropogenic $\mathrm{CO}_{2}$ emissions present a daunting societal challenge with respect to climate change, concentrated $\mathrm{CO}_{2}$ sources also afford an attractive $\mathrm{CO}_{2}$-recycling opportunity. ${ }^{1}$ The electrochemical carbon dioxide reduction reaction $\left(\mathrm{CO}_{2} \mathrm{RR}\right)$ is a catalytic process by which $\mathrm{CO}_{2}$-recycling can be driven via renewably derived electricity, hence affording a pathway toward zero- or low-carbon chemical/fuel feedstocks. ${ }^{2-4}$ For such an approach to have practical utility a host of technical challenges needs to be met, with high chemical selectivity for desired C-containing products being prominent among them. The use of metallic electrodes as catalytic materials is an important strategy to facilitate the transformation of $\mathrm{CO}_{2}$ into a range of such desirable products. ${ }^{5-9}$ Nevertheless, the mechanistic landscape of $\mathrm{CO}_{2} \mathrm{RR}$ is complex and competing protoncoupled electron transfer (PCET) pathways can be operative; control of product selectivity remains a central issue. Approaches to rationally tune the selectivity of catalytic surfaces are needed.

Nanostructuring of metallic surfaces, to increase the number of exposed active sites, has been widely used as a strategy to prepare electrodes with improved reaction kinetics for $\mathrm{CO}_{2} \mathrm{RR} .{ }^{8,10}$

${ }^{14}$ Detailed analyses of the catalytic activity as a function of the electrochemical surface area (ECSA) have suggested that nanostructuring does not alter the intrinsic activity of the active sites in any significant manner. ${ }^{15}$ This observation is in agreement with the fact that the outcome of electrochemical $\mathrm{CO}_{2} \mathrm{RR}$ is determined by the adsorption energies of reaction intermediates, ${ }^{16}$ which are typically correlated through thermodynamic scaling relations. ${ }^{17}$ Strategies to break scaling relations and control reaction pathways to favor a single product are therefore desired. $^{18-20}$
In this context, molecular modifications of electrode surfaces provide an attractive approach for the electrosynthesis of desired products in $\mathrm{CO}_{2} \mathrm{RR}^{21-29}$ Our research team has recently focused on studying the interaction of molecular films with copper electrodes to control the selectivity of $\mathrm{CO}_{2} \mathrm{RR}^{30-32}$ We have disclosed that water-soluble $N$-substituted pyridinium-type additives undergo electrochemically induced reductive dimerization in situ, leading to the deposition of an organic film onto the surface of a polycrystalline $\mathrm{Cu}$ electrode. As a consequence, methane generation is highly suppressed and faradaic efficiencies (FE) for $\mathrm{C}_{2+}$ products can be substantially increased, up to $80 \%{ }^{30}$ Further, when such molecular films are electrodeposited onto copper-based gas diffusion electrodes, it is suggested that selective stabilization of surface intermediate $* \mathrm{CO}_{\text {atop }}$ enhances the electrosynthesis of ethylene, with reaction rates up to 230 $\mathrm{mA} \mathrm{cm}{ }^{-2}{ }^{31}$ These electrodeposited molecular films have also demonstrated utility in the stabilization of nanostructured copper surfaces for the selective production of ethylene. ${ }^{32}$

These results with copper notwithstanding, it remains to now determine whether other metal electrodes can be similarly modified, and if so, how such additives, once deposited, may tailor the electrocatalytic profiles of these metals in the context of $\mathrm{CO}_{2} \mathrm{RR}$ (or other reductive transformations). The simplicity of the approach offers attractive opportunities here. In addition, understanding the mechanistic basis of how such molecular films alter the $\mathrm{CO}_{2} \mathrm{RR}$ selectivity profile may aid in the design of new organic-metal interfaces with tailored selectivities. ${ }^{29,31}$ Studies aimed at building such understanding are complicated by the rich product profile of $\mathrm{CO}_{2} \mathrm{RR}$ on copper electrodes.

By contrast, metallic silver surfaces catalyze primarily $\mathrm{CO}_{2}$-to$\mathrm{CO}$ conversion in aqueous electrolytes, with concomitant production of $\mathrm{H}_{2}$ and a small amount of $\mathrm{HCOOH}$ depending on the 
potential applied. ${ }^{9,33}$ In this regard, comparing modified and unmodified silver electrodes, the former being prepared via a similar additive approach to that which we have explored with copper, provides an appealing strategy for mechanistic studies owing to the simplicity of the product profile. Herein, we explore the mechanistic basis for pyridinium-based additives to attenuate HER at organic-silver interfaces. We show that certain $\mathrm{N}$ substituted pyridinium additives alter the $\mathrm{CO}_{2} \mathrm{RR}$ product profile of $\mathrm{Ag}$ foils by selectively inhibiting proton (HER) but not $\mathrm{CO}_{2}$ reduction within a certain potential window, thereby producing $\mathrm{CO}$ with extremely high selectivity. A mechanistic hypothesis for this effect is proposed based on a combination of electrocatalytic, kinetic, and surface characterization studies.

\section{RESULTS AND DISCUSION}

Selective Electroconversion of $\mathrm{CO}_{2}$ to $\mathrm{CO}$. Bulk electrolysis experiments were performed on a polycrystalline silver electrode with $\mathrm{CO}_{2}$-saturated $0.1 \mathrm{M} \mathrm{KHCO}_{3}$ electrolyte $(\mathrm{pH}=6.8)$ using a recently reported custom flow cell. ${ }^{34}$ Potentials were measured versus a leakless $\mathrm{Ag} / \mathrm{AgCl}$ electrode and converted to the RHE scale according to the equation: $\mathrm{E}_{(\mathrm{RHE})}=\mathrm{E}_{\mathrm{Ag} / \mathrm{AgCl}}+$ $\mathrm{E}^{\mathrm{o}}{ }_{\mathrm{Ag} / \mathrm{AgCl}}+0.059 \mathrm{pH}$; where $\mathrm{E}_{\mathrm{Ag} / \mathrm{AgCl}}$ is the measured potential, $\mathrm{E}_{\mathrm{Ag} / \mathrm{AgCl}}^{\mathrm{o}}=0.1976 \mathrm{~V}$ at $25^{\circ} \mathrm{C}$, and $\mathrm{pH}$ is the $\mathrm{pH}$ value of the bulk. In the absence of a molecular additive, bare silver electrodes produced exclusively $\mathrm{CO}, \mathrm{H}_{2}$, and $\mathrm{HCOOH}$ within the tested potential range (from $-0.80 \mathrm{~V}$ to $-1.20 \mathrm{~V}$, Figure 1a-b, Figure $\mathrm{S} 1$, Table S1). Trace $\mathrm{CH}_{4}$ was detected at higher potential values, consistent with previous reports. ${ }^{9,32}$ The highest FE for CO was obtained at $-1.10 \mathrm{~V}\left(\mathrm{FE}_{\mathrm{CO}}=74 \%\right)$ with concomitant production of $\mathrm{H}_{2}\left(\mathrm{FE}_{\mathrm{H} 2}=19 \%\right)$ and $\mathrm{HCOOH}\left(\mathrm{FE}_{\mathrm{HCOOH}}=3 \%\right)$. At bias more reducing than $-1.20 \mathrm{~V}$ and less negative than -0.90 $\mathrm{V}, \mathrm{H}_{2}$ was the major product and the production of $\mathrm{HCOOH}$ remained constant $\left(\mathrm{FE}_{\mathrm{HCOOH}}<5 \%\right)$.
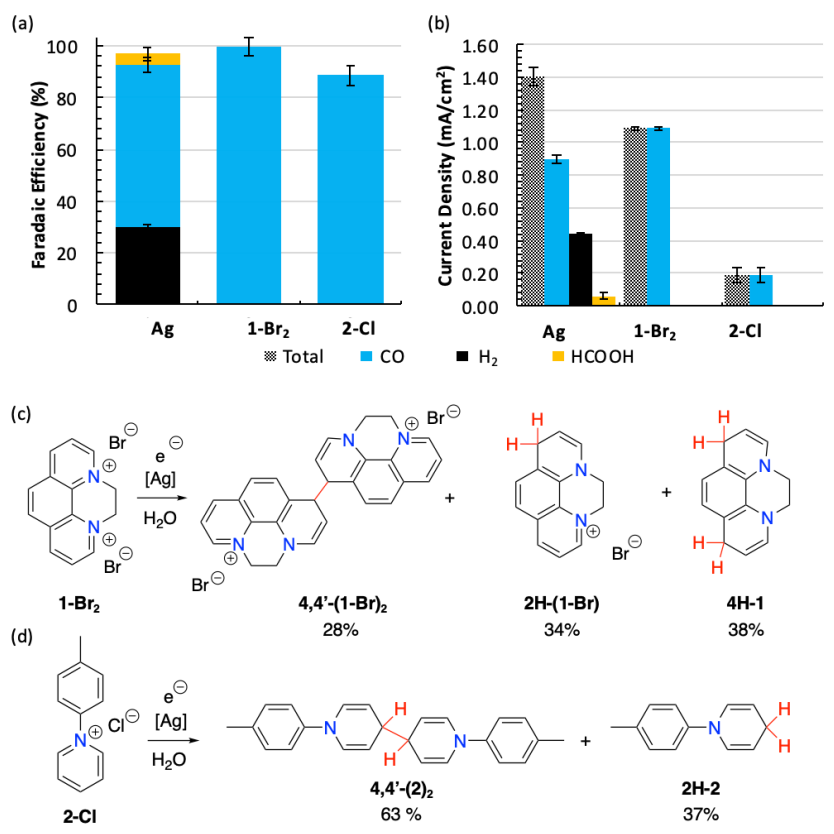

Figure 1. (a) Faradaic efficiencies; (b) total and partial current densities obtained during $\mathrm{CO}_{2} \mathrm{RR}$ at $-0.99 \mathrm{~V}$ in a $\mathrm{CO}_{2}$-saturated $0.1 \mathrm{M}$ $\mathrm{KHCO}_{3}$ electrolyte without or with $10 \mathrm{mM}$ of either $\mathbf{1 - B r} \mathbf{B r}_{2}$ or $\mathbf{2 - C l}$. Chemical structure of $1-\mathrm{Br}_{2}$ (c), 2-Cl (d) and their reduction to 4,4'(1-Br) $)_{2}, 2 \mathrm{H}-(1-\mathrm{Br}), 4 \mathrm{H}-1,4,4^{\prime}-(2)_{2}$ and $2 \mathrm{H}-2$, respectively.
The electrocatalytic performance of Ag foils was then evaluated in the presence of molecular additives using a $10 \mathrm{mM}$ solution of either $\mathbf{1 - B r}$ or 2-Cl (Figure 1, Figure S2 and S3, Table S2 and S3). Similar to our previous studies with copper foils, ${ }^{30,31}$ a noticeable organic film was electrodeposited in situ during catalysis onto the surface of the silver electrodes. Most notably, HER was completely suppressed within the range from -1.00

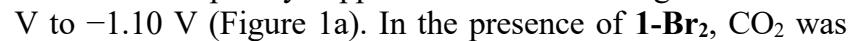
selectively converted to $\mathrm{CO}$ with quantitative FE. Similar selectivities were observed when a silver electrode, previously functionalized with the organic film (by the same above-mentioned protocol), was used in bulk electrolysis experiments together with an additive-free electrolyte, confirming the role of the organic film for suppressing hydrogen production rather than solution based pyridinium (Table S4). In addition, the selectivity was maintained over $24 \mathrm{~h}$ with no detectable $\mathrm{H}_{2}$. The suppression of $\mathrm{H}_{2}$ was also observed under acidic conditions at $\mathrm{pH}$ values as low as 4.2 , in a phosphate buffer at $-1.1 \mathrm{~V}$, highlighting the robustness of these organic films (Table S5).

This hybrid catalytic system represents the first example of a silver electrode that is completely selective (up to our detection limit) for $\mathrm{CO}_{2}$-to-CO electroconversion in $\mathrm{pH}$-neutral aqueous solution. ${ }^{35-39}$ With respect to demonstrating high current densities (up to $300 \mathrm{~mA} / \mathrm{cm}^{-2}$ ), silver-containing gas diffusion electrodes, derived from a Ag coordination polymer, were recently shown to produce $\mathrm{CO}$ at FEs $>96 \%{ }^{40}$

In the presence of molecular additive $\mathbf{1 - B r}$, the partial current density for $\mathrm{CO}\left(j_{\mathrm{CO}}\right)$ increased by $20 \%$ compared to bare silver (Figure 1b), indicating that the molecular film promotes the production of CO. This observation is notable, as it points to a role of the film in tuning selectivity beyond inhibition of $\mathrm{H}_{2}$ evolution. Additionally, the maximum efficiency for $\mathrm{CO}$ is observed at a potential that is anodically shifted by $100 \mathrm{mV}$ relative to that observed for bare Ag. At potentials less negative than -0.85 $\mathrm{V}$ and more reducing than $-1.30 \mathrm{~V}, \mathrm{H}_{2}$ is the predominant product, even though the partial current densities were $30-60 \%$ lower than those measured for bare silver at the same potentials.

The post-catalysis surface compositions of Ag electrodes with and without the additives present in the electrolyte were analyzed ex situ by X-ray photoelectron spectroscopy (XPS, Figure S4). For convenience, the post-catalysis electrodes in the presence of 1-Br $\mathbf{2}$ or 2-Cl are herein abbreviated as Ag-1 and Ag-2. Consistent with previous reports, ${ }^{41-43}$ ex situ post-catalysis XPS spectra of bare Ag and Ag-1 feature two peaks separated by 6 $\mathrm{eV}$ at $368.4 \mathrm{eV}$ and $374.4 \mathrm{eV}$. These peaks correspond to $\mathrm{Ag}$ $3 \mathrm{~d}_{5 / 2}$ and $\mathrm{Ag} 3 \mathrm{~d}_{3 / 2}$, respectively, indicating that $\mathrm{Ag}^{0}$ is predominately present on the surface of both electrodes. By contrast, the Ag 3d peaks could not be observed on Ag-2, likely due to the thick layer of film electrodeposited (note: the organic film produced from additive 2-Cl is significantly thicker than the one formed from $\mathbf{1 - B r} 2$, vide infra). As expected, the XPS spectra of both Ag-1 and Ag-2 feature N 1s peaks due to the presence of the organic layer. The spectrum of Ag-1 consists of one broad $\mathrm{N}$ 1s peak at $400.81 \mathrm{eV}$ which was deconvoluted into two peaks centered at $401.71 \mathrm{eV}$ and $400.71 \mathrm{eV}$. These peaks are assigned to quaternary and tertiary amines, respectively. ${ }^{44,45}$ The ratio of tertiary/quaternary amine is approximatively $3: 2$, which differs from the ratio we have previously observed on an additive-modified $\mathrm{Cu}$ electrode (tertiary/quaternary amine ratio $1: 1)^{32}$ and suggests a different film composition. Surprisingly, the XPS spectrum of Ag-2 consists of one N 1s peak at $403.8 \mathrm{eV}$, ca. 4 $\mathrm{eV}$ higher in energy compared to our previous observation for 
a similarly modified copper electrode. ${ }^{32}$ The $\mathrm{C} 1 \mathrm{~s}$ and $\mathrm{O} 1 \mathrm{~s}$ regions of the XPS spectrum of Ag-2 are also shifted to higher energy. We therefore suspect that the observed shift is due to a charging effect of the surface of the modified silver electrode due to its thickly insulating organic layer. ${ }^{46}$

The organic films could be extracted from post-catalysis Ag electrodes using deuterated DMSO (Ag-1) and dichloromethane (Ag-2) to investigate their chemical composition by ${ }^{1} \mathrm{H}$ NMR spectroscopy (Figure S5-S10). The ${ }^{1} \mathrm{H}$ NMR spectrum of the extracted organic film from Ag-2 revealed the presence of only two species. As previously observed with $\mathrm{Cu}$ electrodes, ${ }^{30}$ the major species corresponds to the 4,4'-coupled dimer [Figure 1d, 4,4'-(2), 63\%]. Interestingly, a minor constituent was unambiguously identified as tolyl-4-dihydro-pyridine (Figure 1d, 2H-2, 36\%). This was further confirmed by independent synthesis of $\mathbf{2 H - 2}$ from the reduction of $\mathbf{2 - C l}$ by $\mathrm{Na}_{2} \mathrm{~S}_{2} \mathrm{O}_{4}$ in basic water and comparison with its published spectrum. ${ }^{47}$

The organic film on Ag-1 proved more complex to analyze. The ${ }^{1} \mathrm{H}$ NMR spectrum of the $\mathrm{d}_{6}$-DMSO-extracted film showed the presence of three primary species (integrated intensity $\sim 95 \%$ of total), along with resonances associated with other trace species. Similar to Ag-2, the characteristic resonances of the previously reported 4,4'-coupled dimer [Figure 1c, 4,4'-(1-Br) were observed $\left(28 \%\right.$ of total). ${ }^{32}$ Surprisingly, the corresponding 2,2'-(1-Br) $)_{2}$ dimeric isomer (not shown in Figure 1) was not detected, contrasting with the findings on copper electrodes. ${ }^{32}$ A previously unobserved set of resonances, similar to, but distinct from 4,4'-(1-Br) 2 , were observed. This species has been tentatively assigned as a mono-reduced $\mathbf{2 H - ( 1 - B r ) ~ ( F i g u r e ~ 1 c , ~}$ $34 \%$, Figure S11). The last set of resonances suggested the presence of a symmetric molecule with an aromatic:alkenyl protons ratio of 1:2. Accordingly, these resonances have been attributed to a doubly-reduced species $\mathbf{4 H - 1}$ (Figure 1c, 38\%). Discussion of these assignments is provided in the Supporting Information. Altogether, the ratio of tertiary/quaternary amine species determined by ${ }^{1} \mathrm{H}$ NMR spectroscopy is $3: 2$, in agreement with the aforementioned XPS data.

The surface of Ag-1 and Ag-2 was also analyzed ex situ by scanning electron microscopy (SEM, Figure 2, Figure S12-14) and atomic force microscopy (AFM, Figure S15) after $65 \mathrm{~min}$ of bulk electrolysis at $-0.99 \mathrm{~V}$. The SEM and AFM images of a $\mathrm{Ag}$ electrode in the absence of additive are relatively similar to a freshly polished electrode with a slight increase in the surface roughness (from $132 \mathrm{~nm}$ to $154 \mathrm{~nm}$ ), indicating only little surface reconstruction during catalysis. ${ }^{33}$ Interestingly, the surface of Ag-1 is partially covered by spherical particles of different sizes (Figure 2a). Our recent study on $\mathrm{Cu}$ electrodes demonstrated that $\mathbf{1 - B r _ { 2 }}$ promotes nanostructuring of $\mathrm{Cu}$ foils by a corrosion mechanism. ${ }^{32}$ However, in the present case, energy dispersive X-ray spectroscopy (EDS) data showed that the observed particles on Ag-1 are composed of carbon and nitrogen and not $\mathrm{Ag}$ (Figure 2c). In addition, the particles were easily washed away by rinsing the electrode with DMSO, confirming that they correspond to the organic film (Figure S13). The height of the particles is estimated to be up to $200 \mathrm{~nm}$ by a crosssectional SEM image of a physical vapor deposited (PVD) Ag electrode, where the organic film was electrodeposited under the aforementioned conditions. In contrast, the SEM images of Ag-2 clearly show a full coverage of the electrode with a thick organic layer (Figure $2 b$ and 2d). The cross-sectional SEM image of Ag-2 shows a porous organic film with a thickness of around $9 \mu \mathrm{m}$. Despite differences in surface coverage and film thickness, both Ag-1 and Ag-2 efficiently suppressed HER. To get a better understanding of how HER is suppressed in the presence of the organic film, mechanistic studies were performed. (a)

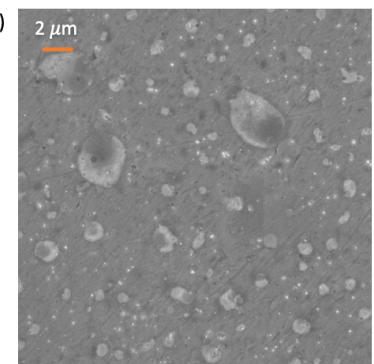

(c)

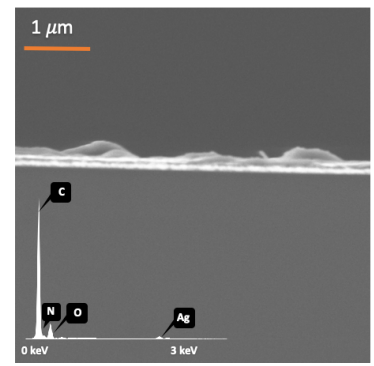

(b)

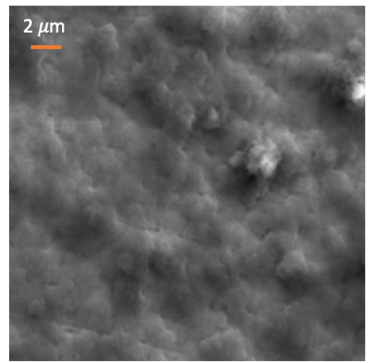

(d)

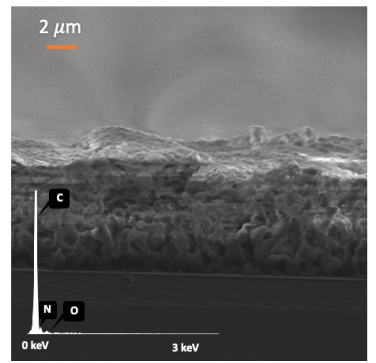

Figure 2. Top view SEM images of (a) Ag-1 and (b) Ag-2. Crosssectional SEM images and inserted EDS spectrum of (c) Ag-1 and (d) Ag-2.

The Organic Film Alters the Rate Determining Step. Current-voltage (Tafel) plots were probed over the potential range from $-0.60 \mathrm{~V}$ to $-1.30 \mathrm{~V}$ (i.e. $0.50>\eta>1.20$ ), for bare $\mathrm{Ag}, \mathbf{A g}$ $\mathbf{1}$ and Ag-2. The Tafel analysis was performed within the linear regime as shown in Figure 3a (see also the Supporting Information and Figure S16). For bare Ag, the obtained Tafel slope $(157 \mathrm{mV} / \mathrm{dec})$ is comparable to previously reported values (130-150 mV/dec), which have been assigned to a rate determining step (RDS) involving an electron transfer (ET) to $\mathrm{CO}_{2}{ }^{36,38,41,48-55}$ In contrast, the Tafel slope obtained with Ag-1 and Ag-2 is significantly smaller $(91 \mathrm{mV} / \mathrm{dec}$ and $107 \mathrm{mV} / \mathrm{dec}$, respectively), indicating improved kinetics for the ET step to $\mathrm{CO}_{2}$. Based on the obtained values for the Tafel slope, it is difficult to unambiguously assign the RDS with Ag-1 and Ag-2. The theoretical value of the Tafel slope for the first ET or PCET as the RDS is $118 \mathrm{mV} / \mathrm{dec}$, while the involvement of a proton transfer (PT) as the RDS results in a value of $59 \mathrm{mV} / \mathrm{dec}^{50,56} \mathrm{In}$ the non-linear region of the Tafel plot at high applied potential (Figure $\mathrm{S} 16$ ), it can be seen that the $\mathrm{CO}_{2} \mathrm{RR}$ activity decreases with increasing potential on Ag, Ag-1 and Ag-2 which likely correlates with a depletion of the ${ }^{*} \mathrm{CO}_{2}{ }^{--}$intermediate. ${ }^{57}$ This could be attributed to an intrinsic issue for $\mathrm{Ag}$ electrodes, where the $\mathrm{CO}_{2}$ concentration is too low at a high applied potential, likely due to a high $\mathrm{CO}_{2} \mathrm{RR}$ reaction rate, to maintain high $\mathrm{CO}_{2} \mathrm{RR}$ selectivity. 

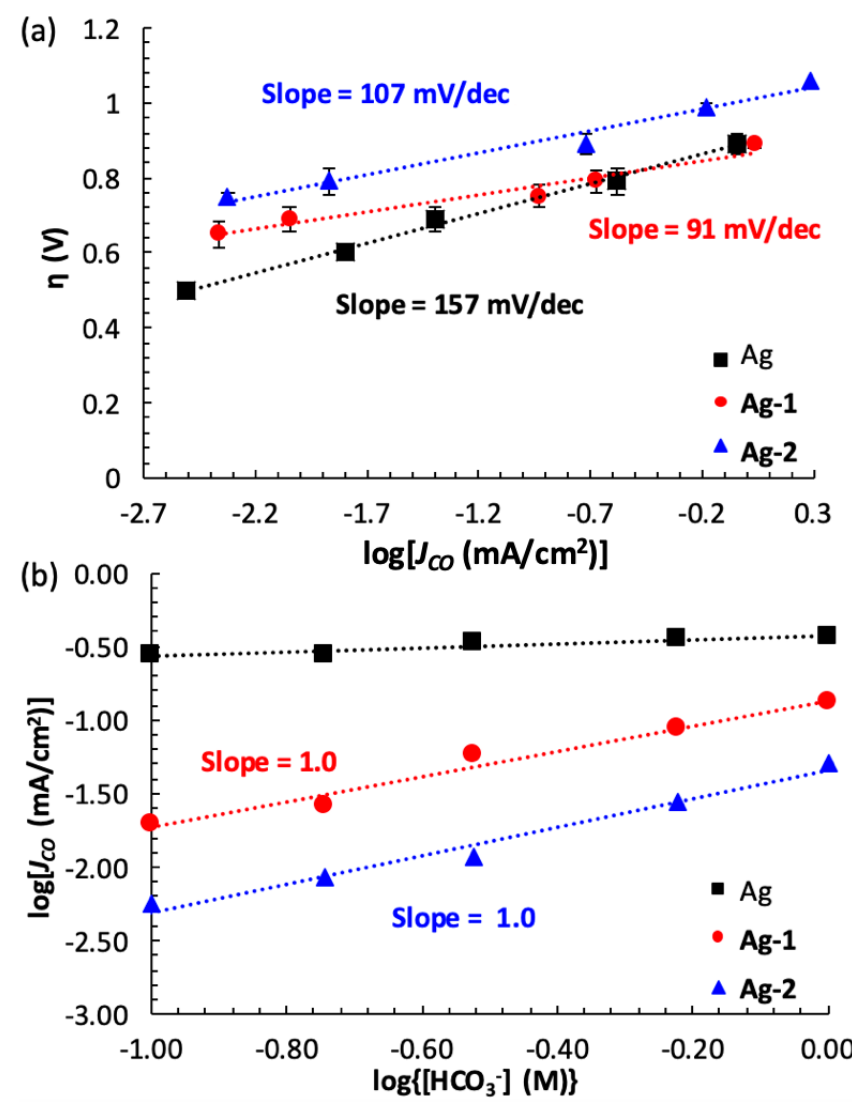

Figure 3. (a) Linear regime of the Tafel plot recorded in $\mathrm{CO}_{2-}$ saturated $0.1 \mathrm{M} \mathrm{KHCO}_{3}$ and (b) $\left[\mathrm{HCO}_{3}{ }^{-}\right]$dependence of the $\mathrm{CO}$ current density recorded at different concentrations of $\mathrm{CO}_{2-}$ saturated $\mathrm{KHCO}_{3}$ electrolyte $(0.1 \mathrm{M}, 0.33 \mathrm{M}, 0.66 \mathrm{M}$ and $1 \mathrm{M})$ at $-0.90 \mathrm{~V}_{\mathrm{NHE}}$ for $\mathrm{Ag}(\boldsymbol{\bullet}), \mathbf{A g}-\mathbf{1}(\bullet)$ and $\mathbf{A g - 2}(\boldsymbol{\Delta})$. Each data point was recorded at least two times to ensure reproducibility. Also see Figure S16 for non-linear behavior at higher applied bias.

The electrodeposition of the molecular film onto the surface of the silver electrode may impose additional mass transport limitation effects, complicating the analysis of electrokinetic studies. To gain further evidence that the partial current density for $\mathrm{CO}_{2} \mathrm{RR}\left(j_{\mathrm{CO}}\right)$ is kinetically controlled within the voltage range of the linear region of the Tafel plot (Figure 3a), we compared the intrinsic activity of bare silver with Ag-2 as a function of the electrodeposition time of the additive. Within a kinetically controlled regime, we expect that the intrinsic activities for $j_{\mathrm{CO}}$ and $j_{\mathrm{H} 2}$ should be independent of the electrodeposition time. To test this hypothesis, $\mathbf{A g - 2}$ was prepared by electrodeposition of 2-Cl during different time intervals (from $10 \mathrm{~ms}$ to $60 \mathrm{~s}$ ) at $0.70 \mathrm{~V}$. This potential was chosen to ensure that all of the consumed current was used to electrodeposit the molecular additive, and not for HER. The electrochemically active surface area (ECSA) was measured before and after the electrodeposition of the film. The $\mathrm{CO}$ and $\mathrm{H}_{2}$ partial current densities were then measured at $-0.9 \mathrm{~V}$, a potential value within the linear range of the Tafel plot (see the Supporting Information for methodology, Figure S24-27, Table S5 and S6). These studies were performed with Ag-2 but not Ag-1 as in the latter case we were unable to reliably control the amount of film electrodeposited on the electrode surface. The instability of the one-electron reduced species (2-Cl) ${ }^{-}$, which increases its propensity for dimerization compared to $(\mathbf{1 - B r})^{--}$, likely contributes to the former's efficacy in controlled film formation.

As the electrodeposition times increase, the ECSA exponentially decreases (vide infra for more discussion). We also noticed that $j_{\mathrm{H} 2}$ and $j_{\mathrm{CO}}$ decrease linearly with the ECSA, showing that the intrinsic activities for $\mathrm{CO}$ and $\mathrm{H}_{2}$ production are constant for any electrodeposition time investigated, and are similar to bare Ag. This behavior indicates that the film does not affect the diffusion rates of proton carriers and $\mathrm{CO}_{2}$ at low overpotentials, thus keeping constant the local concentration of proton carriers and $\mathrm{CO}_{2}$ at the electrode surface, as in the case of a kinetically-controlled regime.

To shed more light on a possible involvement of a proton carrier in the RDS, the influence of the proton donor environment on the $\mathrm{CO}_{2} \mathrm{RR}$ activity was studied. ${ }^{58}$ It has been previously demonstrated that the source of protons could come from $\mathrm{HCO}_{3}{ }^{-14,35,50,56}$ Following previous electrokinetic studies performed on mesoporous electrodes, ${ }^{36,41,48-50,52,56}$ we ran bulk electrolysis at $-0.90 \mathrm{~V}_{\mathrm{NHE}}$, within the kinetic regime, while varying the concentration of $\mathrm{HCO}_{3}{ }^{-}$. Acknowledging that the local concentration of $\mathrm{HCO}_{3}{ }^{-}$at the electrode interface could differ from the bulk due to the diffusion limitations through the molecular film, we have assumed that the local concentration of $\mathrm{HCO}_{3}{ }^{-}$is linearly correlated with the bulk concentration. ${ }^{59}$ The plot of $\log \left(j_{\mathrm{CO}}\right)$ against $\log \left[\mathrm{HCO}_{3}{ }^{-}\right]$exhibits a slope of ca. 1.0 for Ag-1 and $\mathbf{A g}-\mathbf{2}$, and 0 for bare $\mathrm{Ag}$, indicating an approximate first order in $\left[\mathrm{HCO}_{3}{ }^{-}\right]$for $\mathbf{A g - 1}$ and $\mathbf{A g - 2}$ and a zeroth order for Ag (Figure 3b). The data available point to a rate determining step involving a proton transfer from $\mathrm{HCO}_{3}{ }^{-}$to $\mathbf{A g - 1}$ or Ag-2, distinct from bare Ag.

Site Poisoning and the Diffusion Layer Suppress HER. To better understand the mechanism of HER suppression in the presence of the organic film, linear sweep voltammetry (LSV) measurements were recorded in an $\mathrm{N}_{2}$-saturated $0.1 \mathrm{M} \mathrm{KHCO}_{3}$ electrolyte (Figure S20 and S21). Results obtained on bare Ag, Ag-1 and Ag-2 show that the onset potential for HER is shifted up to $400 \mathrm{mV}$ cathodically in the presence of the organic film. Ag-1 displays the lowest HER activity, with current densities 15 times lower than $\mathrm{Ag}$ at $-1.10 \mathrm{~V}$. The possibility of mass transfer limitations induced by the organic film were studied using a rotating disk electrode (RDE). On the bare Ag electrode, the HER current density increased from $-2.2 \mathrm{~mA} / \mathrm{cm}^{2}$ to -5.6 $\mathrm{mA} / \mathrm{cm}^{2}$ upon increasing the rotation speed from $500 \mathrm{rpm}$ to $5000 \mathrm{rpm}$, implying convection mass transport limitation (Figure S22 and S23). In contrast, the HER current density remained constant for Ag-1 and Ag-2, at any rotation speed in this same range, ruling out any convection mass transfer limitation. However, the HER activities for Ag-1 and Ag-2 are 10 to 25 times lower than bare Ag, which could reflect a diffusion mass transport limitation, likely a consequence of the presence of the hydrophobic organic film.

The influence of the partial pressure of $\mathrm{CO}_{2}$ was also studied to compare bare Ag with Ag-1, and Ag-2, to determine whether a mass transport limitation due to the organic film might be operative (Figure $\mathrm{S} 24$ and $\mathrm{S} 25)$. The partial pressure of $\mathrm{CO}_{2}\left(p \mathrm{CO}_{2}\right)$ was varied between $0.2 \mathrm{~atm}$ and $1.0 \mathrm{~atm}$, keeping a constant flow of $5 \mathrm{sccm}$ by using $\mathrm{N}_{2}$ as a balance gas. At $-0.9 \mathrm{~V}_{\mathrm{NHE}}$ and $-1.1 \mathrm{~V}_{\mathrm{NHE}}$, the plot of $j_{\mathrm{CO}}$ as a function of $p \mathrm{CO}_{2}$ gave identical traces for Ag and Ag-1, suggesting that the organic film on Ag1 does not limit the concentration of $\mathrm{CO}_{2}$ close to the electrode surface. In contrast, the trace obtained for Ag-2 is significantly lower than for bare $\mathrm{Ag}$ and $\mathbf{A g - 1}$, indicating that $\mathrm{CO}_{2}$ diffusion 
is limited in the presence of a thicker film. These results explain the lower activity of Ag-2 for CO production in bulk electrolysis experiments compared to Ag-1. It is also worth noting that even at $p \mathrm{CO}_{2}$ as low as 0.2 atm no traces of $\mathrm{H}_{2}$ were detected with Ag-1 and Ag-2, highlighting the ability of these organics films for suppressing HER.

Related to the aforementioned experiments performed to demonstrate that $\mathrm{CO}_{2} \mathrm{RR}$ is under a kinetic regime at $-0.9 \mathrm{~V}$, the correlation between HER current densities and ECSA for different electrodeposition times of 2-Cl were measured at -1.1 $\mathrm{V}$, i.e. under the optimum conditions for $\mathrm{CO}_{2} \mathrm{RR}$ activity. The results show that the ECSA on the Ag electrode decreases exponentially with the electrodeposition time, reaching a plateau where only $40 \%$ of the area remains available (Figure S29a). Accordingly, the HER current density also decreases exponentially with the electrodeposition time (Figure S30). The correlation between the ESCA and the HER current density is shown in Figure 4 (black trace, $\mathbf{m}$, Table S10), where, in contrast to the plot shown in Figure S19, three regimes can be observed. First, the HER current density decreases linearly with the ECSA, until roughly $40 \%$ of the electrode is covered by the organic film. The current density then decreases more sharply, by $\sim 50 \%$, over a very small change in the ECSA. Finally, the value of the HER current density changes very slowly, even as the ECSA is further depleted to ca. $60 \%$ of the total.

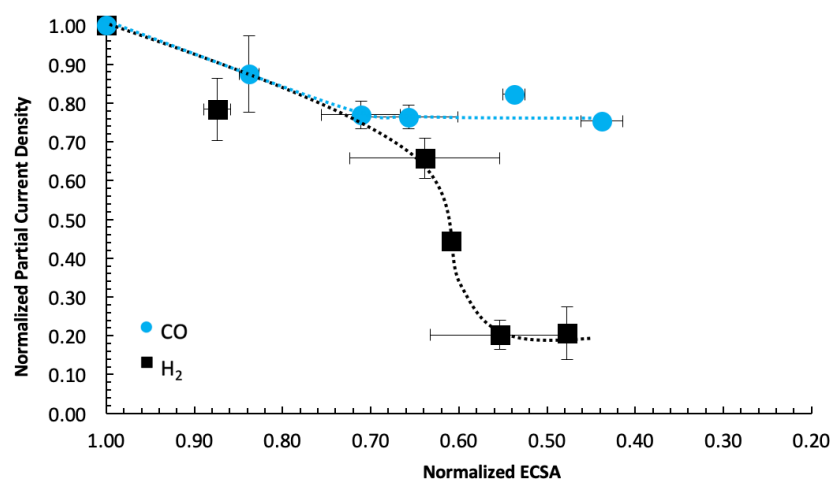

Figure 4. Normalized ECSA against normalized partial current density for HER $(\boldsymbol{\bullet})$ and $\mathrm{CO}(\bullet)$ plot recorded at $-1.1 \mathrm{~V}$. For each experiment, the film was electrodeposited over different time periods $(10 \mathrm{~ms}$ to $1 \mathrm{~min})$ at $-0.70 \mathrm{~V}$ from a $10 \mathrm{mM}$ solution of $\mathbf{2}-\mathbf{C l}$ dissolved in $0.1 \mathrm{M} \mathrm{KHCO}_{3}$. HER experiments were performed under an $\mathrm{N}_{2}$ atmosphere (see the Supporting Info for more details). The dotted lines serve only as a visual guide. Each data point was recorded at least two times to ensure reproducibility.

Similarly, the correlation between $j_{\mathrm{CO}}$ and the ECSA was investigated with Ag-2, using similar reaction conditions as for HER studies but under a $\mathrm{CO}_{2}$ atmosphere (Figure 4, blue trace, $\bullet$, Table S11, Figure S31 and S32). As expected, the ECSA decreases exponentially with the electrodeposition time, indicating that the organic layer is produced independently whether $\mathrm{N}_{2}$ or $\mathrm{CO}_{2}$ is used. The plot of $j_{\mathrm{CO}}$ as a function of the ECSA indicates a linear decrease of $\mathrm{CO}$ production as a function of the active area, until reaching a plateau at an activity that is $\sim 20 \%$ less active than that of bare Ag. Prolonged electrodeposition times reduce only slightly the ECSA without altering the $\mathrm{CO}_{2} \mathrm{RR}$ activity.

The data shown here demonstrate that the film selectively suppresses HER over $\mathrm{CO}_{2} \mathrm{RR}$ at potentials from -1.0 to $-1.2 \mathrm{~V}$.
The data are consistent with a scenario in which the rate of diffusion of protons through a hydrophobic film is dramatically attenuated by comparison to $\mathrm{CO}_{2} \cdot{ }^{58} \mathrm{It}$ is also possible that HER and $\mathrm{CO}_{2} \mathrm{RR}$ occur at distinct active sites ${ }^{60}$ on the silver electrode, with the hydrophobic film preferentially electrodepositing onto and inhibiting HER sites. Our available data do not unambiguously distinguish between such scenarios.

Overall, in the absence of a molecular additive, bare silver electrodes produce a mixture of primarily $\mathrm{CO}$ and $\mathrm{H}_{2}(75 \% \mathrm{CO}$ vs $20 \% \mathrm{H}_{2} ; \sim 5 \% \mathrm{HCOOH}$ at $-0.99 \mathrm{~V}$ ) during $\mathrm{CO}_{2} \mathrm{RR}$. The Tafel analysis, and the zeroth and first order dependence in $\mathrm{HCO}_{3}{ }^{-}$ and $\mathrm{CO}_{2}$, respectively, are consistent with the first ET step to $\mathrm{CO}_{2}$ being the RDS, as previously observed. ${ }^{36,38,41,48-55}$ Figure 5 shows a working mechanistic model for inhibition of HER on the molecularly coated Ag electrodes studied here. At potentials less negative than $-1.0 \mathrm{~V}$, i.e. in the kinetic regime, Tafel analysis suggests improved kinetics for $\mathrm{CO}_{2} \mathrm{RR}$ with $\mathbf{A g - 1}$ and $\mathbf{A g}-$ 2, indicating an enhanced rate for the first ET step that activates $\mathrm{CO}_{2}$. This could be a consequence of interactions (whether direct, or from secondary sphere interactions, for example via water molecules) of the film with $\mathrm{CO}_{2}$ as it is activated and reduced on the Ag surface, analogous to previously proposed activation of $\mathrm{CO}$ at a $\mathrm{Cu}$-film interface. ${ }^{31}$ Electrokinetic data point to the involvement of a proton transfer from $\mathrm{HCO}_{3}{ }^{-}$within the RDS (Figure $5 \mathrm{~b}$ ). At potentials between $-1.0 \mathrm{~V}$ to $-1.2 \mathrm{~V}$, the hydrophobic layer formed from the electrodeposition of the additive limits the diffusion of proton carriers to the electrode surface, but not $\mathrm{CO}_{2}$. Significantly, the production of $\mathrm{H}_{2}$ is completely suppressed, with $\mathrm{CO}$ being selectively generated during $\mathrm{CO}_{2} \mathrm{RR}$. At potentials more reducing than $-1.2 \mathrm{~V}$, the diffusion of $\mathrm{CO}_{2}$ becomes limited, creating a depletion of the ${ }^{*} \mathrm{CO}_{2}{ }^{--}$intermediates (Figure $5 \mathrm{c}$ ). Consequently, the production of $\mathrm{H}_{2}$ becomes more favorable. This working hypothesis warrants testing via future operando spectroscopic measurements that will aid in further characterization of the organic-silver interface.

\section{CONCLUSIONS}

We have reported on a simple and efficient method to fully suppress HER and thereby facilitate $\mathrm{CO}_{2} \mathrm{RR}$ on $\mathrm{Ag}$ electrodes using organic films. The films are conveniently generated at the surface of the silver electrode during bulk electrolysis by in situ reduction of pyridinium-based organic additives. Electrokinetic studies demonstrate the impact of the film on the mechanism of $\mathrm{CO}_{2}$ reduction: a proton transfer from $\mathrm{HCO}_{3}{ }^{-}$is involved in the RDS, which is in contrast to the more typically observed electron transfer as RDS on bare Ag surfaces. Moreover, slow diffusion of proton carriers through the hydrophobic layer is responsible for a dramatic decrease in HER. Consequently, $\mathrm{CO}_{2}$ can be selectively reduced to $\mathrm{CO}$, in an aqueous electrolyte, with FEs $>99 \%$. Structural changes in the additive used result in different film morphologies with distinct consequences on electrocatalysis. For example, the thick film derived from 2-Cl efficiently suppresses HER but also significantly reduces $\mathrm{CO}_{2} \mathrm{RR}$. This detrimental lowering in partial current density for $\mathrm{CO}_{2} \mathrm{RR}$ from 2-Cl is eliminated when the partially covered electrode derived from $\mathbf{1 - \mathbf { B r } _ { 2 }}$ is used instead. The differences observed between $\mathbf{2}-\mathbf{C l}$ and $\mathbf{1}-\mathbf{B r}_{\mathbf{2}}$ highlight the potential for rationally tuning electrocatalysis by functionalizing the electrode with tailored organic additives. 
(a)

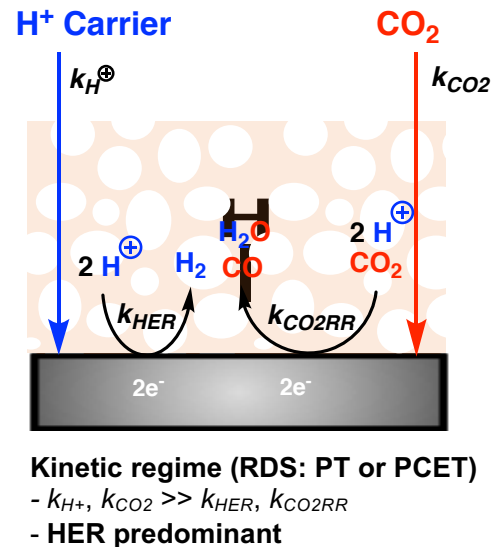

(b)

$-1.0 \mathrm{~V}<$ Voltage $<-1.2 \mathrm{~V}$

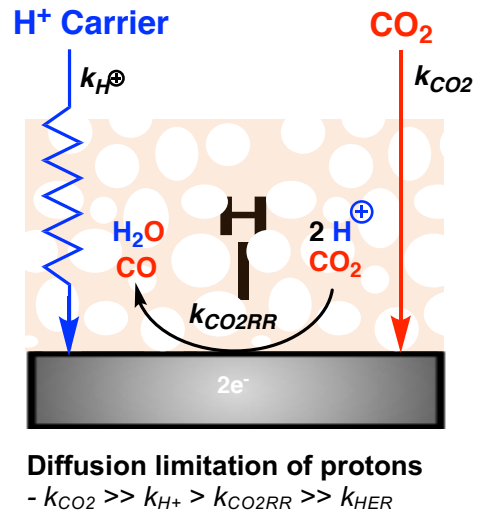

- Higher $\mathrm{CO}_{2} \mathrm{RR}$ rate, HER suppressed (c)

Voltage $>-1.2 \mathrm{~V}$

Figure 5. Our working hypothesis to rationalize $\mathrm{CO}$ and $\mathrm{H}_{2}$ evolution on a polycrystalline silver electrode with the electrodeposited organic film. The Ag electrode and organic film are depicted in gray and orange, respectively. The rate constants $k_{\mathrm{H}^{+}}$and $\mathrm{k}_{\mathrm{CO} 2}$ correspond to the rate of diffusion of proton carriers and $\mathrm{CO}_{2}$, respectively, through the organic film to the electrode interface. The rate constants $k_{H E R}$ and $\mathrm{k}_{\mathrm{CO} 2 \mathrm{RR}}$ correspond to the rate of $\mathrm{HER}$ and $\mathrm{CO}_{2} \mathrm{RR}$ respectively.

\section{ASSOCIATED CONTENT}

\section{Supporting Information}

The Supporting Information is available free of charge on the ACS Publications website.

Experimental details for bulk electrolysis experiments, surface characterization, and additional electrokinetic data (PDF)

\section{AUTHOR INFORMATION}

\section{Corresponding Authors}

*Email: agapie@caltech.edu

*Email:.jpeters@caltech.edu

\section{Author Contributions}

$\dagger$ These authors contributed equally to this work.

\section{Notes}

The authors declare no competing financial interest.

\section{ACKNOWLEDGMENTS}

NMR, AFM, and XPS, SEM and EDX measurements were collected at the NMR Facility (Division of Chemistry and Chemical Engineering), the Molecular Materials Research Center (Beckman Institute) and the Analytic Facilities (Division of Geological and Planetary Sciences) of the California Institute of Technology, respectively. This material is based upon work performed by the Joint Center for Artificial Photosynthesis, a DOE Energy Innovation Hub, supported through the Office of Science of the U.S. Department of Energy under Award Number DE-SC0004993. A.T. acknowledges Marie Skłodowska-Curie Fellowship H2020MSCA-IF-2017 (793471). J.C.P also acknowledges additional support from the Resnick Sustainability Institute at Caltech.

\section{REFERENCES}

(1) Bushuyev, O. S.; De Luna, P.; Dinh, C. T.; Tao, L.; Saur, G.; van de Lagemaat, J.; Kelley, S. O.; Sargent, E. H. What Should We Make with $\mathrm{CO}_{2}$ and How Can We Make It? Joule 2018, 2 , 825-832.
(2) Chu, S.; Cui, Y.; Liu, N. The Path towards Sustainable Energy. Nat. Mater. 2017, 16, 16-22.

(3) Martín, A. J.; Larrazábal, G. O.; Pérez-Ramírez, J. Towards Sustainable Fuels and Chemicals through the Electrochemical Reduction of $\mathrm{CO}_{2}$ : Lessons from Water Electrolysis. Green Chem. 2015, 17, 5114-5130.

(4) Appel, A. M.; Bercaw, J. E.; Bocarsly, A. B.; Dobbek, H.; DuBois, D. L.; Dupuis, M.; Ferry, J. G.; Fujita, E.; Hille, R.; Kenis, P. J. A.; Kerfeld, C. A.; Morris, R. H.; Peden, C. H. F.; Portis, A. R.; Ragsdale, S. W.; Rauchfuss, T. B.; Reek, J. N. H.; Seefeldt, L. C.; Thauer, R. K.; Waldrop, G. L. Frontiers, Opportunities, and Challenges in Biochemical and Chemical Catalysis of $\mathrm{CO}_{2}$ Fixation. Chem. Rev. 2013, 113, 6621-6658.

(5) Nitopi, S.; Bertheussen, E.; Scott, S. B.; Liu, X.; Engstfeld, A. K.; Horch, S.; Seger, B.; Stephens, I. E. L.; Chan, K.; Hahn, C.; Nørskov, J. K.; Jaramillo, T. F.; Chorkendorff, I. Progress and Perspectives of Electrochemical $\mathrm{CO}_{2}$ Reduction on Copper in Aqueous Electrolyte. Chem. Rev. 2019, 119, 7610-7672.

(6) Dinh, C.-T.; Burdyny, T.; Kibria, M. G.; Seifitokaldani, A.; Gabardo, C. M.; García de Arquer, F. P.; Kiani, A.; Edwards, J. P.; De Luna, P.; Bushuyev, O. S.; Zou, C.; Quintero-Bermudez, R.; Pang, Y.; Sinton, D.; Sargent, E. H. $\mathrm{CO}_{2}$ Electroreduction to Ethylene via Hydroxide-Mediated Copper Catalysis at an Abrupt Interface. Science 2018, 360, 783-787.

(7) Yang, K. D.; Lee, C. W.; Jin, K.; Im, S. W.; Nam, K. T. Current Status and Bioinspired Perspective of Electrochemical Conversion of $\mathrm{CO}_{2}$ to a Long-Chain Hydrocarbon. J. Phys. Chem. Lett. 2017, 8, 538-545.

(8) Zhang, L.; Zhao, Z.-J.; Gong, J. Nanostructured Materials for Heterogeneous Electrocatalytic $\mathrm{CO}_{2}$ Reduction and Their Related Reaction Mechanisms. Angew. Chem. Int. Ed. 2017, 56, 11326-11353.

(9) Hori, Y. Electrochemical $\mathrm{CO}_{2}$ Reduction on Metal Electrodes. In Modern Aspects of Electrochemistry; Vayenas, C. G., White, R. E., Gamboa-Aldeco, M.E., Eds.; Springer: New York, 2008; Vol. 42, pp 89-189.

(10) Seh,Z. W.; Kibsgaard, J.; Dickens, C. F.; Chorkendorff, I.; Nørskov, J. K.; Jaramillo, T. F. Combining Theory and Experiment in Electrocatalysis: Insights into Materials Design. Science 2017, 355, eaad4998.

(11) Mistry, H.; Varela, A. S.; Kühl, S.; Strasser, P.; Cuenya, B. R. Nanostructured Electrocatalysts with Tunable Activity and Selectivity. Nat. Rev. Mater. 2016, 1, 16009. 
(12) Mistry, H.; Reske, R.; Zeng, Z.; Zhao, Z.-J.; Greeley, J.; Strasser, P.; Cuenya, B. R. Exceptional Size-Dependent Activity Enhancement in the Electroreduction of $\mathrm{CO}_{2}$ over Au Nanoparticles. J. Am. Chem. Soc. 2014, 136, 16473-16476.

(13) Reske, R.; Mistry, H.; Behafarid, F.; Roldan Cuenya, B.; Strasser, P. Particle Size Effects in the Catalytic Electroreduction of $\mathrm{CO}_{2}$ on $\mathrm{Cu}$ Nanoparticles. J. Am. Chem. Soc. 2014, 136, 6978-6986.

(14) Chen, Y.; Li, C. W.; Kanan, M. W. Aqueous $\mathrm{CO}_{2}$ Reduction at Very Low Overpotential on Oxide-Derived Au Nanoparticles. J. Am. Chem. Soc. 2012, 134, 19969-19972.

(15) Clark, E. L.; Resasco, J.; Landers, A.; Lin, J.; Chung, L.-T.; Walton, A.; Hahn, C.; Jaramillo, T. F.; Bell, A. T. Standards and Protocols for Data Acquisition and Reporting for Studies of the Electrochemical Reduction of Carbon Dioxide. ACS Catal. 2018, 8, 6560-6570.

(16) Peterson, A. A.; Nørskov, J. K. Activity Descriptors for $\mathrm{CO}_{2}$ Electroreduction to Methane on Transition-Metal Catalysts. $J$. Phys. Chem. Lett. 2012, 3, 251-258.

(17) Abild-Pedersen, F.; Greeley, J.; Studt, F.; Rossmeisl, J.; Munter, T. R.; Moses, P. G.; Skúlason, E.; Bligaard, T.; Nørskov, J. K. Scaling Properties of Adsorption Energies for Hydrogen-Containing Molecules on Transition-Metal Surfaces. Phys. Rev. Lett. 2007, 99.

(18) Pérez-Ramírez, J.; López, N. Strategies to Break Linear Scaling Relationships. Nat. Catal. 2019, 2, 971-976.

(19) Pegis, M. L.; Wise, C. F.; Koronkiewicz, B.; Mayer, J. M. Identifying and Breaking Scaling Relations in Molecular Catalysis of Electrochemical Reactions. J. Am. Chem. Soc. 2017, 139, 11000-11003.

(20) Li, Y.; Sun, Q. Recent Advances in Breaking Scaling Relations for Effective Electrochemical Conversion of $\mathrm{CO}_{2}$. Adv. Energy Mater. 2016, 6, 1600463.

(21) Nam, D.-H.; De Luna, P.; Rosas-Hernández, A.; Thevenon, A.; Li, F.; Agapie, T.; Peters, J. C.; Shekhah, O.; Eddaoudi, M.; Sargent, E. H. Molecular Enhancement of Heterogeneous $\mathrm{CO}_{2}$ Reduction. Nat. Mater. 2020, 19, 266-276.

(22) Wang, J.; Zhang, F.; Kang, X.; Chen, S. Organic Functionalization of Metal Catalysts: Enhanced Activity towards Electroreduction of Carbon Dioxide. Curr. Opin.Electrochem. 2019, 13, 40-46.

(23) Cao, Z.; Derrick, J. S.; Xu, J.; Gao, R.; Gong, M.; Nichols, E. M.; Smith, P. T.; Liu, X.; Wen, X.; Copéret, C.; Chang, C. J. Chelating N-Heterocyclic Carbene Ligands Enable Tuning of Electrocatalytic $\mathrm{CO}_{2}$ Reduction to Formate and Carbon Monoxide: Surface Organometallic Chemistry. Angew. Chem. Int. Ed. 2018, 57, 4981-4985.

(24) Ahn, S.; Klyukin, K.; Wakeham, R. J.; Rudd, J. A.; Lewis, A. R.; Alexander, S.; Carla, F.; Alexandrov, V.; Andreoli, E. PolyAmide Modified Copper Foam Electrodes for Enhanced Electrochemical Reduction of Carbon Dioxide. ACS Catal. 2018, 8 , 4132-4142.

(25) Fang, Y.; Flake, J. C. Electrochemical Reduction of $\mathrm{CO}_{2}$ at Functionalized Au Electrodes. J. Am. Chem. Soc. 2017, 139, 3399-3405.

(26) Xie, M.S.; Xia, B. Y.; Li, Y.; Yan, Y.; Yang, Y.; Sun, Q.; Chan, S. H.; Fisher, A.; Wang, X. Amino Acid Modified Copper Electrodes for the Enhanced Selective Electroreduction of Carbon Dioxide towards Hydrocarbons. Energy Environ. Sci. 2016, 9, $1687-1695$

(27) Cao, Z.; Kim, D.; Hong, D.; Yu, Y.; Xu, J.; Lin, S.; Wen, X.; Nichols, E. M.; Jeong, K.; Reimer, J. A.; Yang, P.; Chang, C. J. A Molecular Surface Functionalization Approach to Tuning Nanoparticle Electrocatalysts for Carbon Dioxide Reduction. J. Am. Chem. Soc. 2016, 138, 8120-8125.

(28) Buckley, A. K.; Lee, M.; Cheng, T.; Kazantsev, R. V.; Larson, D. M.; Goddard III, W. A.; Toste, F. D.; Toma, F. M. Electrocatalysis at Organic-Metal Interfaces: Identification of Structure-Reactivity Relationships for $\mathrm{CO}_{2}$ Reduction at Modified Cu Surfaces. J. Am. Chem. Soc. 2019, 141, 7355-7364.
(29) Ovalle, V. J.; Waegele, M. M. Understanding the Impact of $N$ Arylpyridinium Ions on the Selectivity of $\mathrm{CO}_{2}$ Reduction at the $\mathrm{Cu} /$ Electrolyte Interface. J. Phys. Chem. C 2019, 123, 2445324460.

(30) Han, Z.; Kortlever, R.; Chen, H.-Y.; Peters, J. C.; Agapie, T. $\mathrm{CO}_{2}$ Reduction Selective for $\mathrm{C}_{\geq 2}$ Products on Polycrystalline Copper with N-Substituted Pyridinium Additives. ACS Cent. Sci. 2017, 3, 853-859.

(31) Li, F.; Thevenon, A.; Rosas-Hernández, A.; Wang, Z.; Li, Y.; Gabardo, C. M.; Ozden, A.; Dinh, C. T.; Li, J.; Wang, Y.; Edwards, J. P.; Xu, Y.; McCallum, C.; Tao, L.; Liang, Z.-Q.; Luo, M.; Wang, X.; Li, H.; O’Brien, C. P.; Tan, C.-S.; Nam, D.-H.; Quintero-Bermudez, R.; Zhuang, T.-T.; Li, Y.C.; Han,Z.; Britt, R. D.; Sinton, D.; Agapie, T.; Peters, J. C.; Sargent, E. H. Molecular Tuning of $\mathrm{CO}_{2}$-to-Ethylene Conversion. Nature $\mathbf{2 0 2 0}$, 577, 509-513.

(32) Thevenon, A.; Rosas-Hernández, A.; Peters, J. C.; Agapie, T. In-Situ Nanostructuring and Stabilization of Polycrystalline Copper by an Organic Salt Additive Promotes Electrocatalytic $\mathrm{CO}_{2}$ Reduction to Ethylene. Angew. Chem. Int. Ed. 2019, 58, 16952-16958.

(33) Hatsukade, T.; Kuhl, K. P.; Cave, E. R.; Abram, D. N.; Jaramillo, T. F. Insights into the Electrocatalytic Reduction of $\mathrm{CO}_{2}$ on Metallic Silver Surfaces. Phys. Chem. Chem. Phys. 2014, 16, 13814-13819.

(34) Lobaccaro, P.; Singh, M. R.; Clark, E. L.; Kwon, Y.; Bell, A. T.; Ager, J. W. Effects of Temperature and Gas-Liquid Mass Transfer on the Operation of Small Electrochemical Cells for the Quantitative Evaluation of $\mathrm{CO}_{2}$ Reduction Electrocatalysts. Phys. Chem. Chem. Phys. 2016, 18, 26777-26785.

(35) Ma, M.; Liu, K.; Shen, J.; Kas, R.; Smith, W. A. In Situ Fabrication and Reactivation of Highly Selective and Stable Ag Catalysts for Electrochemical $\mathrm{CO}_{2}$ Conversion. ACS Energy Lett. 2018, 3, 1301-1306.

(36) Luan, C.; Shao, Y.; Lu, Q.; Gao, S.; Huang, K.; Wu, H.; Yao, K. High-Performance Carbon Dioxide Electrocatalytic Reduction by Easily Fabricated Large-Scale Silver Nanowire Arrays. ACS Appl. Mater. Interfaces 2018, 10, 17950-17956.

(37) Peng, X.; Karakalos, S. G.; Mustain, W. E. Preferentially Oriented Ag Nanocrystals with Extremely High Activity and Faradaic Efficiency for $\mathrm{CO}_{2}$ Electrochemical Reduction to CO. ACS Appl. Mater. Interfaces 2018, 10, 1734-1742.

(38) Zhang, Y.; Ji, L.; Qiu, W.; Shi, X.; Asiri, A. M.; Sun, X. IodideDerived Nanostructured Silver Promotes Selective and Efficient Carbon Dioxide Conversion into Carbon Monoxide. Chem. Commun. 2018, 54, 2666-2669.

(39) Quan, F.; Xiong, M.; Jia, F.; Zhang, L. Efficient Electroreduction of $\mathrm{CO}_{2}$ on Bulk Silver Electrode in Aqueous Solution via the Inhibition of Hydrogen Evolution. Appl. Surf. Sci. 2017, $399,48-54$

(40) Wang, R.; Haspel, H.; Pustovarenko, A.; Dikhtiarenko, A.; Russkikh, A.; Shterk, G.; Osadchii, D.; Ould-Chikh, S.; Ma, M.; Smith, W. A.; Takanabe, K.; Kapteijn, F.; Gascon, J. Maximizing $\mathrm{Ag}$ Utilization in High-Rate $\mathrm{CO}_{2}$ Electrochemical Reduction with a Coordination Polymer-Mediated Gas Diffusion Electrode. ACS Energy Lett. 2019, 4, 2024-2031.

(41) Hsieh, Y.-C.; Betancourt, L. E.; Senanayake, S. D.; Hu, E.; Zhang, Y.; Xu, W.; Polyansky, D. E. Modification of $\mathrm{CO}_{2} \mathrm{Re}-$ duction Activity of Nanostructured Silver Electrocatalysts by Surface Halide Anions. ACS Appl. Energy Mater. 2019, 2, 102109.

(42) Firet, N. J.; Blommaert, M. A.; Burdyny, T.; Venugopal, A.; Bohra, D.; Longo, A.; Smith, W. A. Operando EXAFS Study Reveals Presence of Oxygen in Oxide-Derived Silver Catalysts for Electrochemical $\mathrm{CO}_{2}$ Reduction. J. Mater. Chem. A 2019, 7, 2597-2607.

(43) Kaspar, T. C.; Droubay, T.; Chambers, S. A.; Bagus, P. S. Spectroscopic Evidence for Ag(III) in Highly Oxidized Silver Films by X-Ray Photoelectron Spectroscopy. J. Phys. Chem. C 2010, $114,21562-21571$. 
(44) Men, S.; Mitchell, D. S.; Lovelock, K. R. J.; Licence, P. X-Ray Photoelectron Spectroscopy of Pyridinium-Based Ionic Liquids: Comparison to Imidazolium- and Pyrrolidinium-Based Analogues. ChemPhysChem 2015, 16, 2211-2218.

(45) Zhao, Y.; Liu, X.; Han, Y. Microporous Carbonaceous Adsorbents for $\mathrm{CO}_{2}$ Separation via Selective Adsorption. RSC Adv. 2015, 5, 30310-30330.

(46) Ferraria, A. M.; Carapeto, A. P.; Botelho do Rego, A. M.X-Ray Photoelectron Spectroscopy: Silver Salts Revisited. Vacuum 2012, 86, 1988-1991.

(47) Park, K. K.; Han, D.; Shin, D. Reduction of N-Arylpyridinium Compounds by Sodium Borohydride and Dithionite: Regioselectivity and Isomerization of Reduction Products. Bull. Korean Chem. Soc. 1986, 7, 201-204.

(48) Lu, Q.; Rosen, J.; Zhou, Y.; Hutchings, G. S.; Kimmel, Y. C.; Chen, J. G.; Jiao, F. A Selective and Efficient Electrocatalyst for Carbon Dioxide Reduction. Nat. Commun. 2014, 5, 3242.

(49) Hsieh, Y.-C.; Senanayake, S. D.; Zhang, Y.; Xu, W .; Polyansky, D. E. Effect of Chloride Anions on the Synthesis and Enhanced Catalytic Activity of Silver Nanocoral Electrodes for $\mathrm{CO}_{2}$ Electroreduction. ACS Catal. 2015, 5, 5349-5356.

(50) Rosen, J.; Hutchings, G. S.; Lu, Q.; Rivera, S.; Zhou, Y.; Vlachos, D. G.; Jiao, F. Mechanistic Insights into the Electrochemical Reduction of $\mathrm{CO}_{2}$ to $\mathrm{CO}$ on Nanostructured Ag Surfaces. ACS Catal. 2015, 5, 4293-4299.

(51) Kim, C.; Jeon, H. S.; Eom, T.; Jee, M. S.; Kim, H.; Friend, C. M.; Min, B. K.; Hwang, Y. J. Achieving Selective and Efficient Electrocatalytic Activity for $\mathrm{CO}_{2}$ Reduction Using Immobilized Silver Nanoparticles. J. Am. Chem. Soc. 2015, 137, 13844 13850.

(52) Ma, M.; Trześniewski, B. J.; Xie, J.; Smith, W. A. Selective and Efficient Reduction of Carbon Dioxide to Carbon Monoxide on Oxide-Derived Nanostructured Silver Electrocatalysts. Angew. Chem. Int. Ed. 2016, 55, 9748-9752.

(53) Liu, S.; Tao, H.; Zeng, L.; Liu, Q.; Xu, Z.; Liu, Q.; Luo, J.-L. Shape-Dependent Electrocatalytic Reduction of $\mathrm{CO}_{2}$ to $\mathrm{CO}$ on Triangular Silver Nanoplates. J. Am. Chem. Soc. 2017, 139, $2160-2163$
(54) Jiang, K.; Kharel, P.; Peng, Y.; Gangishetty, M. K.; Lin, H.-Y. G.; Stavitski, E.; Attenkofer, K.; Wang, H. Silver Nanoparticles with Surface-Bonded Oxygen for Highly Selective $\mathrm{CO}_{2}$ Reduction. ACS Sustain. Chem. Eng. 2017, 5, 8529-8534.

(55) Gao, J.; Zhu, C.; Zhu, M.; Fu, Y.; Huang, H.; Liu, Y.; Kang, Z. Highly Selective and Efficient Electroreduction of Carbon Dioxide to Carbon Monoxide with Phosphate Silver-Derived Coral-like Silver. ACS Sustain. Chem. Eng. 2019, 7, 35363543.

(56) Dunwell, M.; Luc, W.; Yan, Y.; Jiao, F.; Xu, B. Understanding Surface-Mediated Electrochemical Reactions: $\mathrm{CO}_{2}$ Reduction and Beyond. ACS Catal. 2018, 8, 8121-8129.

(57) Liu, X.; Schlexer, P.; Xiao, J.; Ji, Y.; Wang, L.; Sandberg, R. B.; Tang, M.; Brown, K. S.; Peng, H.; Ringe, S.; Hahn, C.; Jaramillo, T. F.; Nørskov, J. K.; Chan, K. PH Effects on the Electrochemical Reduction of $\mathrm{CO}_{(2)}$ towards $\mathrm{C}_{2}$ Products on Stepped Copper. Nat. Commun. 2019, 10, 32.

(58) Yoon, Y.; Hall, A. S.; Surendranath, Y. Tuning of Silver Catalyst Mesostructure Promotes Selective Carbon Dioxide Conversion into Fuels. Angew. Chem. Int. Ed. 2016, 55, 15282-15286.

(59) In the presence of the molecular film, even though the interfacial concentration of $\mathrm{HCO}_{3}-$ might differ from the bulk, due to the diffusion limitations through the molecular film, it is still safe to assume that the interfacial $\mathrm{HCO}_{3}$ - replenished faster than it is consumed since the electrocatalytic experiments were performed in a kinetic-controlled scenario (see reference 50). To determine the order in $\left[\mathrm{HCO}_{3}^{-}\right]$, we assumed that the interfacial concentration of $\mathrm{HCO}_{3}{ }^{-}$varies to the same extent as its bulk concentration when this is changed from $0.1 \mathrm{M}$ to $1.0 \mathrm{M}$. Therefore, we used the value of the bulk concentration of $\left[\mathrm{HCO}_{3}^{-}\right]$in the corresponding kinetic plots.

(60) Wuttig, A.; Yaguchi, M.; Motobayashi, K.; Osawa, M.; Surendranath, Y. Inhibited Proton Transfer Enhances Au-Catalyzed $\mathrm{CO}_{2}$-to-Fuels Selectivity. Proc. Natl. Acad. Sci. 2016, 113, E4585-E4593. 
TOC graphic.

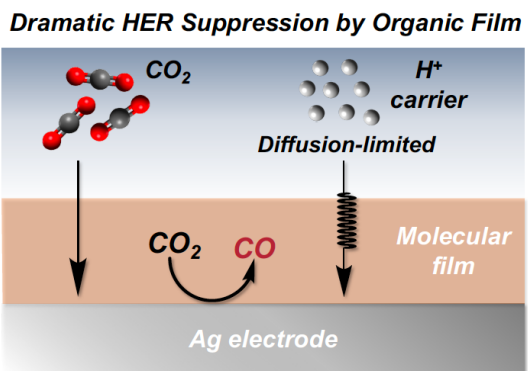

Selective $\mathrm{CO}_{2}$-to-CO Conversion 